\title{
1. A new attitude to law's empire: the potentialities of legal design
}

\author{
Michael Doherty, Marcelo Corrales
}

Compagnucci, Helena Haapio and Margaret Hagan

\section{$1 \quad$ INTRODUCTION}

The philosopher, Ronald Dworkin, argues that 'Law's empire is defined by attitude, not by territory or power or process'. ${ }^{1}$ The chapters in this collection show that design thinking and design methods, as applied to law, constitute a new attitude to law's empire. They demonstrate that legal design can reimagine how we undertake practical lawyering: in creating contracts, in adjudicating disputes, in integrating technology into legal operations and in extending law's protections to consumers and to the most vulnerable. They ask us to move beyond our traditional, culturally inherited, notions of law's empire and to consider from new vantage points more direct relationships between the law and the public it is supposed to serve. They question whether we are training future lawyers to meet the challenges, and to see the potentialities, of these new ways of thinking about law.

Legal design is a movement to make the legal system work better for people. It has been developed out of work in human-centered and visual design, civic technology, and participatory policymaking. It regards the improvement of the legal system on multiple fronts: making it more accessible to lay people, who must use it to resolve problems with money, housing, health, and family; corporate professionals, who use it to contract, litigate, and conduct business; and policymakers and government officials, who use it to set standards, hold powerful interests accountable, and enforce rights and obligations. The purpose of legal design is to develop a human-centered, participatory approach to reforming the legal system, that recognizes the importance of new technology but that does not privilege tech-driven solutions above all others; and that

1 Ronald Dworkin, Law's Empire (1st edn, Belknap Press 1986). 
recognizes the value of interdisciplinary, inclusive groups building and testing new improvements to the system.

The wider theory of change for a design approach to legal system innovation is as follows:

(1) Broader, participatory network. A wider group of professionals (beyond lawyers) and public will be involved in discussions and design of how to reform the legal system, through design events.

(2) Human-centered research of needs and opportunities. This interdisciplinary, participatory network can conduct research into what people's needs and opportunities are, regarding the legal system. This can include research into justiciable events, experiential and process problems, and usability breakdowns.

(3) Exploratory designs. This research then defines an agenda of what new products, services, and policies can make the legal system work better for people. Groups in university labs, public institutions, foundations, small companies, and large existing legal and professional services companies develop and test run these new improvements, using the research to guide them. This is exploratory design and research.

(4) Field pilots and evaluation. Those new interventions and policies that test well in the exploratory stage are then refined sufficiently to be piloted in the field. People's experiences and outcomes are evaluated, to determine if they increase the level and quality of justice, and the efficiency and usability of the system. Outcomes might include people's ability to resolve issues promptly, fully, and collaboratively. It might also be the ability to comprehend and act in the legal system.

(5) Scale and replication. The piloted interventions and policies that are shown through observational and controlled trials to have positive outcomes are then scaled and replicated to be the new standard for how the legal system should operate.

(6) Long-term evaluation. In a longer timeframe, the implementations can be evaluated for larger, downstream implications. Studies can determine if they improve the rule of law, alleviate poverty, improve quality of life, improve the economy, and improve people's relationships with the justice system and wider government.

This vision of legal design is to launch new policy reforms, technology interventions, and service and visual designs that can improve the legal system, through a commitment to a wider participatory public involvement, more focus on people's experiences and outcomes, greater experimentation with technology and design, and gradual refinement of new solutions that pairs creative innovation theory with evidence-based policymaking. In addition to laying out 
what the impact of legal design can be, this theory of change provides the base architecture for methods that can be used.

Legal design is an umbrella term that can mean different things for different people. In the vision presented above, it is seen as part of legal system innovation and access to justice. It can also be seen as part of what is known as proactive/preventive law, enabling the use of legal skills and tools to promote what is desirable and prevent what is not, for example to promote understanding and prevent causes of disputes from arising. In this context, legal design offers tools and techniques to bring user-centered design to legal information, products, and services. In similar ways to what is known as the Four Orders of Design, ${ }^{2}$ the evolution has been from graphic and industrial (product) design to service, information, interface and interaction design, and then to the design of systems, environments, and organizations. Improving legal communication, services, technologies, and solutions to make these more functional, useful, and usable continues to be at the very core of legal design.

For many legal designers, their relationship with law, or more precisely the traditional legal modes, methods, and cultural values they were trained in, is one of dissatisfaction. They are curious about alternatives and excited by interdisciplinary perspectives and techniques. It is important to make the argument, though, that legal design is not a turning away from the law. It often involves a frank and searching examination of law's particular virtues, certainly of the law's own rhetoric and often sternly romantic self-image. We are interested in those characteristics of law that seek to provide direction, certainty, order, justice, and fairness. Legal design involves a turning towards those virtues, but via a critique of existing legal methods. It argues that traditional ways of lawyering have lost their way, or never adequately met the promise of law's rhetoric, or have served their time and cannot take advantage of technologies' promises. It openly searches for tools beyond the existing palette to try, to go back to Dworkin, ${ }^{3}$ to cast the practice of law in its best possible light.

This volume arrives at an interesting time for legal design. All disciplines, and sub-disciplines, evolve. New sub-disciplines, especially those which are created from multi- and interdisciplinary interactions (such as legal design), have a particularly open texture in their emergent phase. This is because the pioneer practitioners (including academics) are not trained in the discipline they are in the process of creating. They bring the diversity of their backgrounds with them. In this book, that diversity in professional backgrounds includes academia, legal design consulting, professional services, and access

\footnotetext{
2 Richard Buchanan, 'Design Research and the New Learning' (2001) 17(4) Design Issues 3.

3 Dworkin (n 1) 139.
} 
to justice activism. Its subject specialisms encompass contracting, consumer protection, legal technology (and machine learning and legal analytics), intellectual property and cultural heritage, legal anthropology and cultural studies, judicial studies, and legal education.

This rich diversity of legal backgrounds and specialisms enters into a dialogue with the known methods and mindsets of design thinking and information, service, product and systems design, at a time when the shared understandings of what legal design is and what it can do are in a phase somewhere between being nascent and established. As new cohorts of legal designers with more formal training in design methods and philosophies graduate (from the Legal Design Lab, the I2J program at Arizona, the PoLI Institute at Vanderbilt, the Laurea University of Applied Sciences Legal Design and Expertise master's degree program, the Legal Design and Innovation Project at Newcastle, and an increasing range of others) and go out into the world, the modes of working, the foundational concepts and methods of legal design will become deeper and more fully realized, but also more crystallized, more regularized.

For now, we can see the outlines and preoccupations of this new field of activity (as described above). They emerge from the discussions and perspectives shared at such foundational events as the Legal Design Summits in Helsinki in 2016-2019, ${ }^{4}$ the Legal Design Geek Conferences in London in 2018 and $2019,{ }^{5}$ and the Legal Design Alliance with its co-created and evolving Manifesto. ${ }^{6}$ These events and processes were in no way reductionist, but rather showed that there is a sufficient commonality of purpose, perspective, and method for a collection such as this to make sense; for drawing a line around certain types of activities and labelling them 'legal design'. We decided to write this book to bring the different dimensions of legal design and its researchers and practitioners together in one resource, and to contribute to the ongoing discussion of how legal design can usefully, practically, and radically represent this new attitude to law's empire.

\section{CHAPTERS}

Each of the chapters collected here addresses different aspects of the above themes and issues.

\footnotetext{
4 Legal Design Summit [www.legaldesignsummit.com] accessed 9 February 2021.

5 Legal Geek, 'Legal Design Geek Conference’ [www.legalgeek.co/legaldesign] accessed 9 February 2021.

$6 \quad$ Legal Design Alliance [www.legaldesignalliance.org] accessed 9 February 2021.
} 
In Chapter 2, 'Prototyping for policy', Margaret Hagan discusses the great potential in combining a design approach with a legal approach, particularly for tackling complex policy challenges. A combined legal and design problem-solving approach goes beyond refining legal communications and services through human-centered design. That is useful, as the application of design to the legal system. But there is another level of work, in which a legal approach - of systematic, critical, and detailed exploration of possible solutions - is combined with a design approach - of creative, empathetic, and experimental work. This can lead to civic innovation work, particularly in the form of prototyping and testing new policies, that is both large-scale and human-centered. This chapter presents literature and examples that detail this developing practice of prototyping for policy, in which human-centered design is adapted and combined with legal analysis to create new policy development.

A cultural studies approach is taken by Michael Doherty in Chapter 3, 'The relationship between legal and design cultures: tension and resolution'. His starting point is the central thesis of legal design: that service design principles and methods can be usefully applied to legal processes. This necessarily involves lawyers commissioning, participating in, and implementing design projects. The chapter examines anthropological and sociological accounts of professional practice and posits that there are some cultural hurdles to developing this law/design relationship. There are identifiable lawyerly attributes and mindsets derived from legal culture. This culture is not homogeneous, but at its heart are themes of precedent, formality, and textual/verbal articulacy. Design has its own cultural tropes including flexibility, experimentation, and visual literacy. The cultural centers of law and design are some distance apart and this tension may be problematic for those seeking design interventions into law. These cultural constructs have significant power, but they also exhibit plasticity. The chapter concludes by examining the potential of both cultural change and exchange to ease the process of introducing human-centered design characteristics into legal practices.

In Chapter 4, 'Legal design for the common good: proactive legal care by design', Helena Haapio, Thomas D Barton and Marcelo Corrales Compagnucci argue that many legal problems are caused by misunderstandings. People do not read complex documents. Even if they do, they may not find what they look for or understand what they find. This chapter shows how proactive legal care can help not only to deal with challenges of complex legal information, but also to improve access to justice and prevent unnecessary problems. Enhancing clients' self-care by promoting their legal literacy is a central strategy for this purpose. Changing how documents are framed and presented is another. The authors propose a new mindset for lawyers, with a focus on the users and on using the law for the advancement of the common good. With this mindset, it becomes natural to look for skills and tools to present legal infor- 
mation in more engaging and actionable ways. Design patterns offer a way to identify and share such tools, for the benefit of lawyers and clients alike.

The role of legal design in tackling challenges related to balancing protection and access while applying intellectual property rights to indigenous dress heritage (DH) is explored by Rosa María Ballardini, Heidi Härkönen and Iiris Kestilä in Chapter 5, 'Intellectual property rights and indigenous dress heritage: towards more social planning types of practices via user-centric approaches'. They address the problems with the current mainstream approach to IPR, where the main focus is on economic incentives, while societal values are generally less considered. The chapter then contextualizes this discourse within the framework of indigenous DH, focusing on Sámi DH. Their analysis shows how moving from a purely economic-centric to a more social-planning type of justification for IPR could help in better reflecting societal values into IP. The chapter concludes by arguing that a design thinking approach would be important to reach this goal and elaborates on how legal design could trigger such positive development.

Joasia Luzak in Chapter 6, 'Tailor-made consumer protection: personalization's impact on the granularity of consumer rules', illustrates how the use of legal design principles and the benefits of modern technology could guide EU policymakers in drafting more effective consumer protection measures, specifically information provisions and information rules. As modern technology enables personalization of online information, the chapter explores the option for this to lead to the rejection of the one-size-fits-all approach embodied by the application of the average consumer benchmark in assessing whether the information was transparent to consumers. The author concludes with a proposal to gradually oblige online traders to provide more granular, personalized information to consumers.

An access to justice activist and practitioner approach is taken by Ashley Treni and Georges Clement in Chapter 7, 'Co-designing digital tools for 21st-century tenant organizing'. They explain how JustFix.nyc builds data-driven tools with tenants and organizers fighting housing displacement in New York City. The chapter analyzes their co-design model, and the process through which they engage tenants and community advocates in human-centered design to create their tools. Using design insights, they have built accessible and user-friendly tools that help tenants gather housing evidence, send notices to landlords, and navigate complex legal processes with clear action steps. The chapter describes their current work in building data policy tools to observe patterns of harassment by negligent landlords.

In Chapter 8, 'Knowledge graphs as an example of legal design to model legal analytics for adjudication with respect for the rule of law', Geneviève Vanderstichele discusses legal design in the development of legal analytical tools for dispute resolution, starting from a study using a legal knowledge 
graph in the creation of an algorithm to predict the legal ground in criminal cases. Legal analytics are legal information tools that ultimately influence how law is made and administered in disputes. As such, legal analytics are design hybrids, encompassing principles of information design and product design. The chapter proposes to extend the definition of legal design to encompass the creation of legal analytics. Furthermore, it is claimed that, by applying design principles, a debate about the data, the questions, and the choices for the natural language and machine learning algorithm can be facilitated, thus enhancing the rule of law in online societies. The arguments are based on concepts of the philosophy of information and the logic of design.

The practical and conceptual relationship between contracting and legal design is explored by Konsta Huovinen in Chapter 9, 'Better commercial contracts with the application of functional contracting and legal design'. The chapter presents two alternative ways to think about B2B commercial contracting: functional contracting and legal design. These approaches challenge the current contracting practice that is based on safeguard contracting. The overemphasis on the safeguard function in contracts has led to a situation where the design of commercial contracts is not optimal for the business purposes of companies. Current contracts lack user-friendliness and do not acknowledge all the functions of commercial contracts. Functional contracting and legal design recognize the many functions of contracts, and thus, the application of these two allows us to design and draft better commercial contracts.

Chapter 10, 'Legal design in judicial decisions: the Colombian case study' by Mariana Bernal Fandiño, explores how and why judicial decisions in Colombia are extremely complex and long. It argues that this situation creates a failure in the communication of the result of the disputes and creates a judicial accumulation of unsolved cases. The judicial reasoning in decisions in Colombia is explained in a very complex language, using repetitive arguments and unnecessary references, among other problems. The chapter proposes that a proactive law approach combined with tools of legal design will help prevent or solve these difficulties. Simplification, information design, and visualization offer solutions to simplify judicial decisions, making them easier to understand and more efficient for the system.

In the final chapter, 'Legal design in education: way of teaching and role of different disciplines in building legal design competence', Sanna Niinikoski and Nina Toivonen ask: What is the skillset of a legal designer? What are our goals when teaching legal design? Are we simply teaching design thinking or something more distinctively legal? By applying design principles, methods, and tools, we can create user-friendly legal work products and services, but we also need to know the legal rationale and the desired human behavior the legal design solution should promote. For this reason, they argue, legal design education should lead to an understanding of law and behavioral sciences by com- 
bining these different approaches into a single problem-solving model. The chapter discusses ways to build legal design competence with the right content using the lessons learned from the Legal Design and Expertise master's degree program in Laurea University of Applied Sciences in Finland.

\section{BIBLIOGRAPHY}

Buchanan R, 'Design Research and the New Learning' (2001) 17(4) Design Issues 3 Dworkin R, Law's Empire (1st edn, Belknap Press 1986)

Legal Design Alliance [www.legaldesignalliance.org] accessed 9 February 2021

Legal Design Summit [www.legaldesignsummit.com] accessed 9 February 2021

Legal Geek, 'Legal Design Geek Conference' [www.legalgeek.co/legaldesign] accessed 9 February 2021 